WellBeing International

WBI Studies Repository

2015

\title{
The Role of Professionalization Regarding Female Exploitation in the Nonhuman Animal Rights Movement
}

Corey Lee Wrenn

Colorado State University, corey.wrenn@gmail.com

Follow this and additional works at: https://www.wellbeingintlstudiesrepository.org/anirmov

Part of the Animal Studies Commons, Civic and Community Engagement Commons, and the Politics and Social Change Commons

\section{Recommended Citation}

Wrenn, C. L. (2015). The role of professionalization regarding female exploitation in the Nonhuman Animal rights movement. Journal of Gender Studies, 24(2), 131-146.

This material is brought to you for free and open access by WellBeing International. It has been accepted for inclusion by an authorized administrator of the WBI Studies Repository. For more information, please contact wbisr-info@wellbeingintl.org.

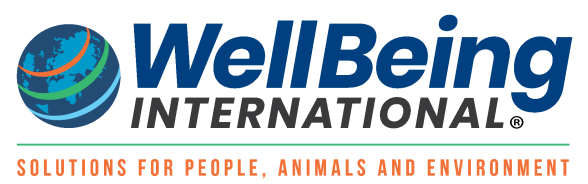




\title{
The Role of Professionalization Regarding Female Exploitation in the Nonhuman Animal Rights Movement
}

\author{
Corey Lee Wrenn \\ Colorado State University
}

\begin{abstract}
KEYWORDS
animal rights, gender, objectification, professionalization, social movements, sexualization

ABSTRACT
\end{abstract}

\begin{abstract}
Adams (2004, The pornography of meat. London: The Continuum International Publishing Group Ltd), Deckha (2008, Disturbing images: PETA and the feminist ethics of animal advocacy. Ethics and the environment, 13(2), 35-76), Gaarder (2011, Women and the animal rights movement. Piscataway, NJ: Rutgers University Press), Glasser (2011, Tied oppressions: an analysis of how sexist imagery reinforces speciesist sentiment. The Brock review, 12(1), 51-68), and others have criticized People for the Ethical Treatment of Animals (PETA) for sexually exploiting young women in outreach and fundraising efforts. This article extends these critiques in addressing the problematic relationship between objectified volunteer female activists and Nonhuman Animal rights organizations (Animal Liberation Victoria, Fish Love, LUSH, and PETA). These organizations have largely professionalized and have consequently refocused their priorities on fundraising for organizational maintenance. An exploration into the social movement literature on the phenomenon of professionalization casts the use of young women's bodies for financial gains in a more troubling light. The Nonhuman Animal rights industry that exploits the sexuality of female activists ultimately exploits archetypes of women as nurturers and temptresses. These groups also utilize women's vulnerability by targeting female consumers and their sensitivity to body image. This article places female objectification within the logic of social movement professionalization. These organizations merge advocacy with capitalist interests to the ultimate disadvantage of women and Nonhuman Animals alike. The exploitation of female stereotypes and ultimately the female body, it is argued, is ineffective in challenging ideologies of oppression as both a practical and a theoretical matter.
\end{abstract}

\section{Introduction}

Women and Nonhuman Animal ${ }^{1}$ rights activism have been linked since the inception of the movement in the nineteenth century (Elston 1987, Ferguson 1998, Gaarder 2011). In positioning themselves as natural 
caregivers particularly suited to attending to social reforms, many women were able to break free, to some extent, from their restriction to the domestic sphere (Unger 2012). From very early on, then, some female Nonhuman Animal rights activists have used feminine stereotypes as leverage in their advocacy (Ferguson 1998, Beers 2006). In the modern movement, this nurturing role remains, but women have also adapted their identity as a sexualized object of consumption to push Nonhuman Animal rights (Gaarder 2011). Today, both archetypes of women as caring, motherly figures and sexual temptresses operate in tandem and ground women in the realm of nature and nonhumans. The problem in this relationship is the dehumanizing effect on female activists and the reinforcement of unequal power structures that thrive on these stereotypes. Female vulnerability has become a movement resource. As vegan feminist scholar Carol Adams notes on the largest Nonhuman Animal rights organization, People for the Ethical Treatment of Animals (PETA): 'PETA sells women's inequality; PETA sells Playboy. PETA is selling women's inequality' (2004, p. 166).

This article explores the representation of women in the Nonhuman Animal rights industry, which I define as an aggregate of financially focused charities that prioritize revenue over efficacy. In particular, I explore how socially constructed gender roles have been manipulated to advance the cause. While PETA has been heavily analyzed (Adams 2004, Deckha 2008, Gaarder 2011, Glasser 2011), there has not been adequate attention given to how sexist representations have actually become movement normative. I highlight equally troubling campaigns led by Animal Liberation Victoria (ALV), Fish Love, and LUSH as well as PETA.

In addition to opening up the dialog on sexism in the Nonhuman Animal rights movement beyond PETA's infamy, I position these representations as an intentionally designed and increasingly favored social movement tactic. Leadership in the Nonhuman Animal rights movement is largely male despite the majority of participants being female (Gaarder 2011). Many social movements relegate female participants to the drudgery of organizational tasks with men enjoying leadership positions (Lawson and Barton 1980), but the Nonhuman Animal rights movement seems to be abusing this power differential in normalizing the sexualization of women's activism and targeting women's vulnerability and insecurity as consumers.

In Making A Killing: The Political Economy of Animal Rights, Torres (2006) describes the modern Nonhuman Animal rights movement as an 'animal rights industry' to draw attention to the tendency for Nonhuman Animal charities to prioritize resource mobilization over tactical efficacy. Mobilization for the rights of other animals is inextricably embedded in capitalism, and empathy for other animals has become commoditized. This has largely been the result of social movement professionalization. As an organization bureaucratizes, emphasis shifts from social change to organizational maintenance and survival (McCarthy and Zald 1973). This phenomenon has entailed significant compromise for liberation efforts by weakening goals (Francione 1996), but also in undermining equality and the integrity of female activists.

I argue that the professionalization of the Nonhuman Animal rights movement is related to the exploitation of female activists: The professionalized organization must prioritize survival, and 'selling' female vulnerability is thought to ensure consistent revenue and public resonance. The Nonhuman Animal rights movement taps into masculine mobilization efforts (such as direct action and reasoned-based discourse), and female exploitation might be seen as an extension of that patriarchal framework. This type of advocacy is relegated mainly to the mainstream, professionalized Nonhuman Animal rights industry that recycles profits into further fundraising campaigns. Women's bodies become the means of soliciting donations and public support and women's bodies also act as the targets of campaigning (and thus benefit fundraising). PETA's campaign to ban 'fur, ${ }^{2}$ for example, is promoted through advertisements featuring nude women who would, 'rather go naked than wear fur.' Those same advertisements target a 
largely female consumer base - a population often subject to harassment and intimidation as a result of the increasingly normative nature of women's sexual victimization (Koss et al. 1994). Exposure to popular violent media, for example, has been linked to men's acceptance of violence against women as well as their acceptance of rape culture (Malamuth and Check 1981). Campaigns intended to blame or even terrorize women who consume nonvegan products could have dangerous consequences. Simultaneously, body-centric Nonhuman Animal rights advertising reinforces the feminine fixation on body image. In equating women's self-worth to their physical attractiveness, this approach creates a toxic environment for women.

Thus, female activists' bodies are used to promote the organization in campaigning, while women's bodies in the general public are also exploited for organizational gain. The foundations for this organizational behavior, it is argued, stem from a history of sexist stereotypes that view women as caregivers and seductresses. These stereotypes, in turn, are adopted by a professionalized movement organization with a narrow focus on bottom line fundraising. This is unfavorable not only for the advancement of women's status, but also for the advancement of other animals' status and the fortification of healthy, fulfilling, and sustainable activism.

\section{Women, nonhumans, and nature}

The exploitation of women in the professionalized Nonhuman Animal rights movement likely has its roots in a historical heritage of female stereotypes. For centuries, women have been linked to the earthly realm (Merchant 1980, Gaard 1993). This association could be seen in the beautiful, fertile, bountiful, inspirational, maternal, or romanticized qualities applied to both nature and women. Yet, they were also portrayed as seducing, dangerous, and destructive. The archetype of women as caregivers and mothers is linked to the life cycles observed in nature. Certainly, this connection resulted in relatively high statuses for some women in pre-Christian eras where they were often represented as religious leaders and goddesses (Gimbutas 1991). Woman as temptress, however, has some origins in folklore and religious stories. This archetype may have been intended to protect male dominance by framing women as dangerous and predatory, thus obscuring men's vulnerability (Billinghurst 2003). Perhaps one of the most important examples is that of Christianity's Eve, whose liaisons with the snakes and fruit of the garden resulted in an eternity of misery for humankind.

The Enlightenment era aggravated this negative perception as scientific endeavors categorized, objectified, and reified the natural world (Merchant 1980). The feminine was frequently linked with all that was dangerously alluring in nature and necessitated regulation and restraint. This had unfortunate implications for the status of women, and many previously positive connections to the feminine were also stigmatized. Women were often blamed for natural disasters, community crises, and the fallibility of men. Successful women were sometimes held in suspicion of witchcraft and evildoing. The connection to the natural world also reinforced the notion that women were resources - they both produced and embodied resources to be consumed (Denys 2011).

The feminine natural world has existed in a dichotomy with the cultured, more 'sophisticated' world - the realm of men. These links become problematic in becoming justifications for the unequal status attributed to womanhood: ' . . . the pan-cultural devaluation of woman could be accounted for, quite simply, by postulating that woman is being identified with, or symbolically associated with, nature, as opposed to man, who is identified with culture' (Ortner 1972, pp. 11 and 12). Oftentimes, the relationship of culture and nature is one whereby culture subsumes and conquers nature. Consequently, woman's subservience to man is seen as 'natural' and becomes a taken for granted norm. Thus, women often become dehumanized, devalued, objectified, and certainly trivialized as a result of their socially constructed connection to the natural world. 
Neither archetype of femininity is wholly favorable, and both tend to objectify and restrict women's identity. While a social movement may find it easy to tap into female identities that view women as contemptible resources in need of control and manipulation, to do so is to engage in a historical project of sexism against women. However, it appears that this utilization is becoming a normative tactic in the professionalized Nonhuman Animal rights movement, perhaps in part due to the large pool of female activists upon which it can draw.

\section{Gender in the Nonhuman Animal rights movement}

A major facilitator of this exploitation is the perceived association between women and Nonhuman Animal rights activism. Gender norms and socialization processes that reinforce this ideological relationship between women and nature (Peek et al. 1996) have continued into the modern popular consciousness and media representations (Reynolds and Haslam 2011). As a result, women have become indelibly linked to nonhuman activism (Jackson 1993). Some women have worked within this framework, while others have utilized the stereotype as a stepping stone to greater influence. Still others reject this link, relying instead on a schema of oppression to challenge speciesism.

Regency and Victorian women involved in the scientific study of nature were encouraged to frame their work in a manner that reflected feminine gender norms of domesticity and morality (Gianquitto 2007). During the American Progressive Era, however, women manipulated their domestic role to act as 'civic housekeepers' for environmental, Nonhuman Animal, and social welfare issues (Unger 2012). By the turn of the century, hundreds of women's conservation clubs were in existence. While women's fashion in feathered hats pushed many species to the brink of extinction, it was also women who spearheaded efforts to protect those endangered birds (Price 1999). Alternatively, some feminists, notably Frances Power Cobbe, drew parallels between the experiences of women and other animals. Specifically, Cobbe saw connections in the manifestations of violence and the ways science had oppressed and harmed both groups. She urged other feminists to widen their scope of concern to include other animals, and even denounced the campaign to integrate women into the medical academy if vivisection were to go unchallenged (Mitchel 2004).

The end of the Progressive Era also saw a retraction in women's civic power, but the connection between women and the natural world would resurface during the Civil Rights era (Unger 2012). Emerging in response to the similar experiences of oppression and oftentimes rooted in the cultural pretense that women and the nonhuman world share a 'natural' affinity (Merchant 1980), ecofeminism has become a popular subfield in environmental studies and advocacy. Ecofeminism argues that nature is dominated in much the same way as women (and other oppressed groups) and challenges hierarchical thinking (Adams 1991, Gaard 1993, Hawkins 1998). Patriarchy is targeted as the oppressive system that exploits and devalues both women and nature. Classifications and distinctions that rigidly define and otherize nature and species are seen as patriarchal creations (Goldman and Schurman 2000).

Recognizing the interconnectedness of life, vegan ecofeminism extends concern to Nonhuman Animals in particular (Gaard 1993). The 'ethic of care' was established as a feminist alternative to masculine rightsbased approaches to environmental and animal advocacy (Donovan and Adams 2007). Many ecofeminists such as Gaard (1993) and Donovan and Adams (2007) suggest that Nonhuman Animal liberation is implicit to a feminist critique of environmental exploitation. Embracing the female affinity to nature as a liberatory measure, however, risks reinforcing unhelpful stereotypes, as Cuomo (1998) warns: 'In the process of exploring and creating ethical options and alternatives, reclamations of traditional ideas and practices might be helpful, but they must be critically evaluated in terms of present contexts as well as their historical embeddedness' (p. 39). 
Thus, while the special connection between women and the nonhuman realm is a human-made connection, the consequences of that construction are certainly real. Caring about Nonhuman Animals has become a normative expectation for women. It is no surprise, then, that women are disproportionately represented in Nonhuman Animal rights activism (Gaarder 2011). Luke (2007) furthers that nonhuman activism (largely female) is often pitted against the very male-oriented industries of exploitation ('hunting,' vivisection, slaughtering, etc.). Public perceptions of nonhuman activism reinforce the notion that advocacy for other animals is 'women's work.' As Groves (2001) finds, this female involvement is often seen as irrational, overly emotional, and largely ignorant of the 'necessity' of nonhuman use in men's realms. Striking gender stereotypes thus emerge that act as powerful counterframes in discrediting Nonhuman Animal activism and demotivating participation. The protection of Nonhuman Animal exploitation becomes almost synonymous with protecting patriarchy. In response, Nonhuman Animal rights activism has utilized this gendered reality to advance their interests. This is accomplished in at least three ways: men are elevated into leadership to enrich movement credibility, masculine aggression and assertiveness is exploited for risky activism, and female bodies are objectified to garner attention from men and media.

The strong presence of women in the Nonhuman Animal rights movement is interesting if we consider that men have been traditionally associated with the cultural realm. Because men are not bogged down the 'burdens' of reproduction, they are supposedly freed to operate and advance society (de Beauvoir 1961). This seems contradictory to the large demographic of women in the movement. However, when we look at the higher, more prestigious positions in nonhuman activism, we see that they are disproportionately occupied by men (Gaarder 2011). Leadership, theory development, and frontline, dramatic, and public activism is a largely male endeavor for many social movements (Lawson and Barton 1980, West and Blumberg 1990), but its occurrence within the female-dominated Nonhuman Animal movement is striking, given the largely female constituency. Luke (2007) posits that men tend to conduct most Nonhuman Animal exploitation in an attempt to give life (albeit negatively) through the perceived community benefits of Nonhuman Animal sacrifice (providing food with 'hunting' and slaughter and advancing medicine with vivisection). This is thought to be an attempt to counter and surpass the decidedly more positive ways that women give life through birth and breastfeeding. Women's biological ability to create life becomes a feminine source of power that must be dismissed and overcome to protect patriarchy. Perhaps male leadership in Nonhuman Animal activism, then, represents, the social norm for men to lead, but also grants men the privilege to control what is essentially a nature-focused and lifeaffirming 'feminine' movement.

Regardless of any ambitions men may personally hold for upward mobility in the movement, women tend to encourage the presence of men in prestigious and influential roles (Groves 2001, Gaarder 2011). Due to the negative stereotypes of femininity associated with the nonhuman movement, the more 'credible' male presence is perceived as essential in building legitimacy. This comes at the expense of meaningful participation from many female advocates, and men may be pushed into influential positions regardless of qualifications or suitability. This practice can also lead to a devaluation of female contributions (Gaarder 2011), the validation of inaccurate gender stereotypes, and the discouraging or downplaying of female potential.

Some factions exploit gendered expectations of masculinity to recruit young men to the movement. Hall (2006) suggests that aggressiveness, assertiveness, independence, and disregard for authority commonly associated with young male identity are harnessed by groups such as the Animal Liberation Front that utilize direct action and violent tactics. Gaarder's (2011) study finds additional support for the valorization of masculine advocacy in Nonhuman Animal rights. Certainly, the masculine fetishization of violence is also tied to the large number of young men activists in these groups. By appealing to the male 
identity, such groups convince young men who are less concerned with social consequences to take on great risks for the group. Indeed, direct action and violent tactics carry the very real possibility of legal recourse and incarceration (Lovitz 2010). This masculine identity is encouraged as a means for legitimizing subjugation and compliance (Hall 2006). It is presumed that threatening language, violent actions, and other displays of power can force or coerce government institutions and the public to accept their demands for Nonhuman Animal liberation. Hall (2006) and others (Francione 1996) have insisted that such tactics are decidedly antithetical to the goal of nonviolence and equality for all.

While the exploitation of masculine identity in Nonhuman Animal rights activism is certainly problematic, the groups perpetuating it tend to be clandestine, unprofessionalized, and (at least publicly) condemned by the mainstream movement (Guither 1998, Munro 2005). Thus, number of participants are low and the negative consequences might be contained. The overwhelming unpopularity of violent activism, negative media portrayals, and heavy legal counteraction could also restrict the reach of Nonhuman Animal rights hypermasculinity. More importantly, because a patriarchal society ultimately benefits men and women have a history of experiencing severe inequality, the impact of gender exploitation on men, while important, is substantially less devastating. This is especially so as the mainstream Nonhuman Animal rights industry (that almost exclusively utilizes female bodies over male bodies) has a much larger media presence.

Therefore, while some underground groups have played on expectations of male aggression, and virtually all groups tend to celebrate male leadership, female objectification is a pervasive gender issue in Nonhuman Animal rights simply due to the power of larger groups and the exposure they are able to generate. These large organizations are the face of the movement: they define a movement's agenda and help shape public perceptions.

\section{Female vulnerability and exploitation as a tactic}

\section{Body image and objectification}

The potential consequences of gender typing in Nonhuman Animal rights activism are numerous. In an examination of sexist PETA campaigning, Deckha (2008) suggests that some sexualized images of women can be moderately useful in promoting rights for other animals. She cites PETA's 'Milk Gone Wild' campaign as an example of one advertisement that invites the audience to think critically rather than to objectify. The advertisement parodies the commercials for the mainstream pornography collection Girls Gone Wild. It features scantily clad and inebriated young women persuaded by men with video recorders and cameras to flash breasts made to look like cow's udders. ${ }^{3}$ The actresses are portrayed in dark bars and bathrooms touching themselves suggestively, pulling at their underwear, and squirting breast milk onto men and into men's mouths. Men are shown gazing, fondling, licking, and kissing the shirtless women. On the 'Milk Gone Wild' website, a text box promoting the consumption of beer (as a healthier alternative to cow's milk) is juxtaposed with this embedded video. Alcohol, of course, is the most widely used date rape drug (ScienceDaily 2007) and intoxicated individuals cannot give consent (taking advantage of an intoxicated person sexually is a felony offense; Preventing Rape by Intoxication through Community Education 2009). To promote alcohol consumption alongside images of inebriated women who are coerced by men to strip (the women are depicted as initially resistant, but eventually succumb to the experience and appear to enjoy it) is to romanticize crimes against women and to facilitate rape culture. For these reasons, I strongly disagree that the sexist and violent connotations of the campaign hold any meaningful potential for effective advocacy on behalf of other animals.

However, Deckha does point to PETA's anti-'fur' campaign as problematic in sexualizing the white female body and perpetuating harmful gender norms and standards of beauty. Harper (2010), too, notes that the 
Nonhuman Animal rights movement has created an idealized 'vegan body' that normalizes whiteness and thinness. This ideal alienates other body types and people of color. Moreover, the thin, white, vegan female body further sexualizes and objectifies the role of women in the nonhuman movement. Campaigns that prey on women's self-consciousness about their physique reinforce the notion that women are valued only in the sexual desirability of their bodies. PETA's (2009) 'Save the Whales' Florida billboard, for example, targeted female beachgoers who would undoubtedly be especially sensitive to their body image. The billboard read 'Lose the blubber' and featured a headless female torso squeezed into a revealing bikini. This advertisement fragments the female body, and, in 'reducing' women to the status of nonhumans, it reinforces the notion that self-worth is found in a sexually desirable body. Similarly, the bestselling Skinny Bitch series (Freedman and Barnouin 2005) masks a vegan message in a body-centric approach that, as the name implies, priorities thinness and attractiveness and celebrates women's competition with one another for male attention. Like the PETA billboard, women are likened to Nonhuman Animals (bitches) in a derogatory manner. The cover boasts an illustration of an unrealistically pencil-thin white female figure.

Perhaps the most notorious instance of female objectification in Nonhuman Animal advocacy is PETA's 'Id Rather Go Naked than Wear Fur' campaign. Supposedly, highly sexualized photographs of female celebrities renouncing their taste for the hair of other animals will convince other women (who are the primary wearers of 'fur') to renounce 'fur' themselves. While PETA might be the most visible offender, it is hardly alone. Fish Love, a UK based fishery conservation organization, hosts a photographic project that positions naked celebrities (mostly white, thin females) with the corpses of sea animals. VGirls|VGuys, a multimedia project and online community intended to promote veganism, hosts several photographs of female and male vegan models. As of this writing, female models far outnumber that of men (37 to 15), and the female models are more likely to be posed in a sexually provocative manner wearing lingerie or other revealing clothing. In one promotional video, two women are shown dancing on a stripper pole in lingerie. ${ }^{4}$ The featured men are less likely to be shown unclothed. Of the seven men who are shown shirtless, with exposed chest, or in a bathing suit, three appear to be displaying body art and the others are professional athletes. Of the 37 featured women, only 2 are not pictured in their underwear or in a revealing bathing suit. Some were naked.

It is worth noting that male celebrities are included as subject matter in many of these campaigns. However, they are in the minority and those few who are included are pictured in dominant poses demonstrating command over their space. Deckha (2008) notes that men in PETA advertisements are generally framed humorously, they are not sexualized, and beauty standards are not encouraged as they are in their gynocentric counterparts. The integrity and social power of male models and demonstrators is not undermined. Female activists, however, are routinely objectified and their bodies displayed for public consumption, which is presumed to encourage public interest and donations. Female consumers, too, find their own bodies scrutinized and treated as objects at the behest of the professionalized Nonhuman Animal rights movement.

\section{Sexualization}

Perhaps because sexualized media has been linked to increased rates of body dissatisfaction among women (Turner et al. 1997, Groesz et al. 2002, Holmstrom 2004, Aubrey et al. 2009), these images might be intended to coerce women into compliance through shame or envy. But because women are pictured naked in postures that convey submissiveness or sexual availability, the status of women in general is also imperiled.

The superabundance of sexualized female representations in the media is associated with prejudice and violence against women (Malamuth and Check 1981, Lanis and Covell 1995, MacKay and Covell 1997, 
Kalof 1999, Ward 2002). Adams (2004) adds that PETA's campaigns '[ . . ] can be said to create hostile environments for women, reproducing the fragmented woman' (p. 166). Beyond their 'fur' campaign, the use of naked female bodies in their promotion has also spread to other issues such as circuses, exotic skins, and veganism. In one advertisement, PETA (N.d. a) enlisted pornography actress Jenna Jameson to promote pleather. She is described as '[ . . . ] a strong, sexually aware woman.' PETA adds, 'If you're looking for some advice on how to add some flare in the bedroom, she is the perfect expert to get help from.' When PETA marks an adult film star as an expert on female sexuality and ' $[. .$.$] living proof that$ pleather certainly is sexy [ . . . ]' they are intentionally drawing on unrealistic and largely harmful portrayals of women in pornography as normal, desirable, and enviable.

In 2012, PETA launched a pornography site that paired their scantily clad female models with horrific scenes of Nonhuman Animal suffering. In a disclaimer, PETA insisted that an .xxx domain name was vital for garnering attention (Halverson 2012). ${ }^{5}$ PETA UK also held a public demonstration in London's Trafalgar Square featuring two Playboy models naked in a bathtub to promote veganism as a means for water conservation (Sherrow 2011). PETA is not the only business mixing Nonhuman Animal activism with adult entertainment. In Portland, Oregon, a vegan strip club services men with nude female Nonhuman Animal lovers (Bindel 2011).

In another example of entangled sex and activism, demonstrations carried out by female activists of Australian organization ALV were glamorized in the 'Love \& Lust Issue' of CLEO, a sex, relationship, and lifestyle magazine for women (Gawthorne 2008). ${ }^{6}$ The story, depicting vivid images of bound and bloodied naked bodies of female activists, was included among articles on 'what men want' and how to achieve a 'sexier body.'

LUSH, a soap and cosmetic company catering to vegans, held a global promotion where employees (mostly female) were encouraged to distribute leaflets to the public on reduced product packaging, wearing nothing but aprons (Pinsker 2008). In one promotional video, the employees were shown photographed by the public (LUSH 2007). In another video taken at a New Zealand store, the employees were all female and many were in high heels (Angmaiaxander 2008). They were paraded past staring men who were clearly not in the market for high-end perfumed soaps or bath bombs. Indeed, because many LUSH products are still in packaging and because leafleting is antithetical to conservation, one is left to question the real motives of such a campaign.

Finally, in 2012, ALV launched their 'Milk Sucks' campaign which included a public demonstration of a female activist positioned under a life-size fiberglass cow pretending to suck the teats (Animal Liberation Victoria 2012). The sexual innuendo was not lost on her audience, as evidenced in a Florida Sportsman ${ }^{7}$ forum poll titled 'Would you date this girl?' (Fishonhenson 2012). The majority of respondents voted yes. Comments included 'Depends, I need to see the top half of her first,' 'I need to see the bottom half too,' 'I can't wait to see what she does to the burro,' 'I wonder if she swallows . . ., and 'I'm witholding [sic] my vote until we see how she does with the bull.' The sexualizing tactics of professionalized organizations, therefore, may indeed garner attention. However, that attention tends to be dehumanizing, and the attempt at shocking or tantalizing the public into organizational support seriously undermines women's integrity.

\section{Sexualized violence}

The aforementioned ALV feature in CLEO Magazine speaks of another disturbing trend in Nonhuman Animal rights activism: the naked female body is sometimes portrayed in scenes of graphic violence. Women in PETA advertisements are shown chained to the bed, holding bloodied corpses of murdered Nonhuman Animals, lifeless on morgue tables, pierced by banderillas, or lying in pools of blood. In the 
Fish Love campaign, there is something striking about the display of naked women holding, straddling, or wearing the bodies of dead sea animals which are normally considered food. In an ALV protest against Japanese whaling, a female demonstrator was made to appear naked and was completely covered with dripping bright red paint (Hastie 2008). ALV routinely utilizes nude women in their demonstrations - and oftentimes these women are portrayed as victims of violence. Female activists have posed naked to protest against 'fur' consumption, sometimes crouching in cages (The Age 2008). In one demonstration, women were literally labeled as 'meat,' lying plastic wrapped, naked, and drenched in fake blood. In another, a woman partially covered by a white sheet was mounted on a mock-up of a vivisection restraint, again, doused in fake blood (The Age 2007). In 2012, LUSH hosted a street performance as part of their 'Fighting Animal Testing' campaign. A young woman wearing a nude bodysuit was 'tortured' by a male actor in the store window for 10 hours (Omond 2012a). The sexualization of the female form in activism for other animals, then, is often embedded within normalized violence against women.

Some activists and researchers have been critical of the escalation (Adams 2004, Luke 2007, Gaarder 2011). Luke (2007), for example, posits that the Nonhuman Animal exploiters (largely men) targeted by such campaigns are not seriously challenged in their actions and are simply given the privilege to visually consume the young, thin, vegan bodies on display for their attention. Objectification, sexualization, subjugation, and patriarchy all remain intact and are fully reinforced by the Nonhuman Animal rights industry in using these tactics. Adams elaborates: 'They place women in cages, encouraging the human male to experience himself as superior' (2004, p. 166). Male privilege, she assures, remains unchallenged.

PETA defends the nude campaigns in their ability to 'consistently grab headlines' (PETA N.d. b). Women's tie to the natural world as both nurturer and temptress has become lucrative. As 'natural' caretakers, women become the ambassadors of Nonhuman Animal rights. But, as part of their nurturer role, they are expected to tend to the needs of men, as well as nonhumans. Women embody the Nonhuman Animal rights movement as the rank and file and perform the mundane, but necessary, organizational work. However, perceived as seductresses of the earthly realm, women have become sexualized beings available for sex and in need of domination even in the social movement environment. Women become vital instruments to activism in appearing naked and victimized with the hopes of drawing attention and luring men to the cause. Thus, we see that these traditional archetypes have resurfaced in an era of Nonhuman Animal mobilization and have been reformulated for movement advertising and advantage.

\section{Professionalization in the Nonhuman Animal rights movement}

I have argued that the female body is, to the Nonhuman Animal rights movement, an object for display, a thing for consumption, and a promotional item. As we have seen, the exploitation of gender roles is commonplace in the Nonhuman Animal rights movement, even for those smaller and less influential factions. However, it could be the case that professionalization, an organizational progress toward a rationalized business-like structure (Zald and Ash 1966, McCarthy and Zald 1973), has predisposed the mainstream nonhuman movement toward sexual objectification. Policies promulgated by major media organizations are steered by the pursuit of economic profit, and the power to manipulate content lies squarely with the owners (Shoemaker and Reese 1996). Social movement organizations, I argue, operate similarly in implementing tactics shaped by the pursuit of resources where campaign content is controlled by powerful organizational leaders. Adams (2004) suggests that Nonhuman Animal rights organizations simply reflect the dominant culture they inhabit: 'PETA draws on all the pornographic conventions that advertisers draw upon' (p. 166). Sex in advertising is ubiquitous - it sells in a patriarchal society where masculinity is tied to virility and femininity is tied to sexual availability and attractiveness. In a 2011 study, Hatton and Trautner found that women in the media are increasingly sexualized. Thus, if an organization 
must advertise to support itself, it becomes quite understandable that an organization would draw on popular culture and standard advertising methods to survive. Unfortunately, women's lowly social status has been a very popular resource for business success.

Professionalization is characteristic of many social movements and has been documented in the Nonhuman Animal rights movement as well (Francione 1996, Guither 1998, Torres 2006). In the harsh social movement environment, where resources and support fluctuate and many organizations are in competition for limited resources, some degree of organization is needed to assure a group's survival (Staggenborg 1988). Strong organization heightens the group's ability to accumulate resources and strengthen activist identity. Regrettably, a necessary drawback to professionalization is the moderation in goals as an organization must appeal to a larger constituency to support a larger overhead. Furthermore, radical frameworks are unlikely to succeed in the short run and thus have limited ability in bringing immediate gain for an organization. Quickly won victories are essential for a professionalized organization's fundraising obligations.

Moderation in professionalized organizations can extend beyond goal attainment and impact tactical standards as well. For example, rarely do any professionalized Nonhuman Animal rights organizations explicitly advocate veganism (Francione 1996). Instead, most push vegetarianism or reductionism even though these tactics have been criticized as essentially condoning the continued exploitation of nonhumans (Francione 1996). While veganism is sometimes promoted, it is just as often vilified (Francione and Garner 2010). Veganism represents a call for radical social change that major organizations perceive as alienating to their donor base. Therefore, they tend to distance themselves from veganism when fundraising remains paramount.

Thus, there is little opportunity for professionalized organizations to rock the boat in the competitive and uncertain social movement environment. Challenging the subjugation of women necessarily takes the back seat to the socially acceptable (and profitable) trend in exploiting them (D'Enbeau 2011). But the exploitation of women extends beyond naked images, violent demonstrations, and pornography. Some sexualized campaigns are doubly problematic in that they objectify female volunteers and also vilify female consumers. For instance, while most humans, regardless of gender, openly wear some form of Nonhuman Animal flesh ('fur,' 'leather,' 'silk,' 'suede,' or 'wool'), Nonhuman Animal groups tend to focus on 'fur' - a product primarily promoted to, and subsequently worn by, women. Francione (1996) explains this contradiction:

The fur industry is certainly indefensible according to any moral standard (other than an extreme form of ethical egoism), but using sexist imagery or assaults on women to make that point is extremely problematic not only because it is violent but because men wearing their expensive wool suits need not worry about animal rights advocates harassing them. (p. 75)

Women's bodies are used to promote anti-'fur' campaigns and women's bodies become the target of these same campaigns. LUSH's Fighting Animal Testing campaign takes a similar route in exploiting the female consumer. As explained on their website, it was intentional that the torture victim used in their aforementioned street performance was female:

We felt it was important, strong, well and thoroughly considered that the test subject was a woman. This is important within the context of Lush's wider Fighting Animal Testing campaign, which challenges consumers of cosmetics to feel, to think and to demand that the cosmetics industry is animal cruelty free. It is also important in the context Jacqui's performance practice: a public art intervention about the nature of power and abuse. It 
would have been disingenuous at best to have pretended that a male subject could represent such systemic abuse. (Omond 2012b)

Indeed, even the Victorian era campaigns to protect birds killed for the hat trade chastised female consumers for their consumption of cruel fashion (Unger 2012). Singling out women as foci of activist aggression makes for easy, low-risk activism and, thus, easy returns in exposure and fundraising. ${ }^{8}$ The female consumer stands in as the 'other,' an accessible representation of Nonhuman Animal exploitation. If professionalized organizations were to target male consumers, one could speculate that the public would be less supportive and fundraising would be threatened. ${ }^{9}$ Much of the Nonhuman Animal industry's hypersexualization of the female body could be seen as a reinforcement of men's dominance meant to protect fundraising pools.

In their fundraising activities, the Nonhuman Animal industry exploits the vulnerability of women in using them as sexualized promotional items and targets for easy victories. If this exploitation could at least be understood as a sacrifice for Nonhuman Animal liberation, perhaps it would not appear so devious. Yet, comparatively little of the money raised is allocated to advancing Nonhuman Animal rights (Francione 1996, Guither 1998). Organizational professionalization requires that a substantial amount of mobilized income be reserved for business expenses and further fundraising activities. Women are degraded 'for the animals' without compensation, and very little indirect compensation is realized in advancing the rights of other animals. It is therefore suggested that some Nonhuman Animal groups prostitute the female body for organizational gain. Women, whether willing or not, offer their bodies for the consumption of exploiters as well as for retaliation when the women represent the exploiters themselves. It is the professionalized group that pockets the profits.

\section{Conclusion}

The Nonhuman Animal rights industry (led mainly by men) has tapped into the connection between women and Nonhuman Animals by recruiting primarily female volunteers for public outreach and fundraising activities. In overtly sexualizing female activists, organizations have exploited the traditional archetypes of women as nurturers and temptresses. Women are expected to nurture Nonhuman Animals, but also the needs of male movement leaders and male potential constituents. Women are seen as temptresses from Eden and teasing sirens on rocky isles with the cunning ability to lure men into veganism and anti-speciesism.

Because this approach exploits restrictive and often demeaning or demonizing female archetypes, the sexualization and objectification of female volunteers is particularly problematic. However, PETA and other Nonhuman Animal rights groups are, in one important way, quite typical of professionalized organizations in other social movements. They experience a hyperfocus on fundraising as concerns regarding organizational survival trump rational and efficient tactics and goals. Thus, it has become the case that female volunteers are valued primarily for their physical bodies as sexual objects to be presented to the public to solicit donations. Organizations 'selling' the bodies of these young women receive media attention and financial return. Meanwhile, the women on display become depersonalized stereotypes and living billboards. The women outside the movement suffer as targets of harassment and hatred. All women suffer as inhabitants of a sexist world that victimizes and objectifies women: a toxic environment that the Nonhuman Animal rights movement has helped perpetuate.

Thus, female exploitation in mobilization efforts is, in many ways, counterintuitive: 'Misogynistic tactics are ultimately self-defeating. Women have always been the backbone of animal advocacy, and thus the use of techniques that disempower women can only undermine the long-term viability of the movement' (Luke 2007, p. 216). Indeed, Deckha (2008) has speculated that PETA's sexist campaigning could alienate 
rather than attract women. This is particularly tragic given that social movement participation and Nonhuman Animal activism can be empowering, rewarding, and identity forming. It is also a lamentable squandering of a wellspring of potential contributions in creativity, talents, and skills that female participants might offer. Activism on behalf of other animals could be a liberatory and transformative experience for women. Instead, it often reinforces patriarchy and gender discrimination.

The atmosphere created by Nonhuman Animal professionalization also degrades and limits men's reaction to an important social problem. Men outside the movement are expected to benefit in the enjoyment of gazing on naked vegan bodies or in performing better in bed (many PETA ads promote the sexual benefits of veganism; Haller 2012). They are discouraged from experiencing the gratification possible from challenging the oppression of others. They are also left in the dark about the potential for improving their own physical and mental health in adopting a vegan diet and lifestyle. Male exposure to Nonhuman Animal rights is framed in such a way that men themselves are degraded when they are constructed as mindless sexual consumers. As Adams suggests:

PETA recycles the idea of the 'naturalized' man in hopes that one aspect of his behavior can be overcome (exploiting animals). Ironically, they implicitly endorse the idea that men's sexuality is animal-like, needing release through masturbation, and thus perpetuate a misunderstanding of both Nonhuman Animals and of sexuality. (2004, p. 166)

Ignoring the more affirmative allure of personal improvement and social responsibility, sexually exploitative activism traps men in gendered stereotypes, belittles their potential contributions and benefits, and stifles what could otherwise be a complex and fulfilling experience with Nonhuman Animal rights.

More importantly, however, this sexist approach short-changes those Nonhuman Animals the movement is intended to represent. Nonhuman Animals experience significant prejudice, discrimination, bodily harm, and death as a result of speciesist ideology. Various forms of oppression are thought to operate under similar state-supported socioeconomic systems (Nibert 2002). A sexually exploitative approach actually perpetuates systems of oppression in making the irrational presumption that reinforcing women's inequality could alleviate Nonhuman Animal inequality. Glasser (2011) suggests that in oppressing other disadvantaged groups to further its own aims, PETA ultimately subverts its fundamental goals and puts complementary movements at odds with one another:

This is particularly problematic because oppressions are interlocking and mutually reinforcing within an overarching system of domination. Therefore, when any social justice movement asserts privilege over another social justice movement it hurts all movements fighting oppression. (p. 52)

In serving as yet another venue for human female oppression, sexually exploitative Nonhuman Animal rights activism, a product of movement professionalization, arguably aggravates the social inequality they exist to oppose.

\section{Notes}

1. The term 'Nonhuman Animals' is capitalized to indicate that these individuals constitute a distinct social group.

2. Recognizing that language has the power to otherize (Nibert 2002), I have placed disparaging and euphemistic terms in quotation marks. For this same reason, I have insisted on eschewing the term 
'animals' in favor of 'Nonhuman Animals' or 'other animals.' Though this encumbers the reading at times, it is my intention to challenge normalized oppression in common language.

3. http://www.milkgonewild.com/.

4. http://www.facebook.com/v/10150425905880030.

5. As of this writing, the PETA.xxx site only contains graphic clips of Nonhuman Animal rights issues and no longer features nude women.

6. Analogous to the American magazine Cosmopolitan.

7. This online community frequently overlays sexualized images of women with violence against other animals.

8. While many female consumers are targeted for their consumption of unethical products, Luke (2007) notes that cosmetics, 'fur,' and other items associated with female beauty are actually tied to patriarchy. The ability to purchase these exploitative 'luxury' items for women to display is seen as a demonstration of status. Furthermore, women are pressured to consume these products in fulfilling their role as a decorated object of the male gaze.

9. Luke (2007) notes that while cosmetics marketed to women are far less likely to have been tested on other animals, male consumers are rarely targeted. This is especially troubling given LUSH's explicit desire to target female consumers.

\section{Notes on contributor}

Corey Lee Wrenn is an Instructor in Sociology with Colorado State University in Fort Collins, Colorado. She is currently pursuing a Ph.D. in Sociology at Colorado State University. She received her BA in Political Science from Virginia Tech in 2005 and her MS in Sociology from Virginia Tech in 2008. Her research interests include social movements and nonhuman animals and society.

\section{References}

Adams, C., 1991. Ecofeminism and the eating of animals. Hypatia, 6 (1), 125-145.

Adams, C., 2004. The pornography of meat. London: The Continuum International Publishing Group Ltd.

Angmaiaxander, 2008. Lush Christchurch go naked! YouTube [online]. Available from: http://www.youtube.com/watch?v1/4T9q5Q5rM-SE [Accessed 25 November 2012].

Animal Liberation Victoria, 2012. Milk sucks campaign launched. Story Archive [online]. Available from: http://www.alv.org.au/storyarchive/0702milk/milk.php [Accessed 12 December 2012].

Aubrey, J. et al., 2009. A picture is worth twenty words (about the self): testing the priming influence of visual sexual objectification on women's self-objectification. Communication research reports, 26, 271284.

Beers, D., 2006. For the prevention of cruelty: the history and legacy of animal rights activism in the United States. Athens, $\mathrm{OH}$ : Ohio University Press.

Billinghurst, J., 2003. Temptress: from the original bad girls to women on top. Vancouver: Greystone Books.

Bindel, J., 2011. The world's first vegan strip club. The Guardian [online]. September 27. Available from: http://www.guardian.co.uk/lifeandstyle/2011/sep/27/vegan-strip-club [Accessed 20 August 2012].

Cuomo, C., 1998. Feminism and ecological communities: an ethic of flourishing. New York, NY: Routledge. 
de Beauvoir, S., 1961. The second sex. New York, NY: Bantam Books.

Deckha, M., 2008. Disturbing images: PETA and the feminist ethics of animal advocacy. Ethics and the environment, 13 (2), 35-76.

D'Enbeau, S., 2011. Sex, feminism, and advertising: the politics of advertising feminism in a competitive marketplace. Journal of communication inquiry, 35 (1), 53-69.

Denys, P., 2011. Animals and women as meat. The Brock review, 12 (1), 44-50.

Donovan, J. and Adams, C., 2007. The feminist care tradition in animal ethics. New York, NY: Columbia University Press.

Elston, M., 1987. Women and anti-vivisection in Victorian England, 1870-1900. In: N. Rupke, ed Vivisection in historical perspective. London: Routledge, 259-294.

Ferguson, M., 1998. Animal advocacy and Englishwomen, 1780-1900: patriots, nation, and empire. Ann Arbor, MI: University of Michigan Press.

Fishonhenson, 2012. Would you date this girl? Florida Sportsman Forums [online]. Available from: http://www.forums.floridasportsman.com/showthread.php?47622-would-you-date-thisgirl\&s¹/414459dfb7693a3279aeeb459eacd2221 [Accessed 12 December 2012].

Francione, G., 1996. Rain without thunder: the ideology of the animal rights movement. Philadelphia, PA: Temple University Press.

Francione, G. and Garner, R., 2010. The animal rights debate: abolition or regulation? New York, NY: Columbia University Press.

Freedman, R. and Barnouin, K., 2005. Skinny bitch. Philadelphia, PA: Running Press.

Gaard, G., 1993. Ecofeminism: women, animals, nature. Philadelphia, PA: Temple University Press.

Gaarder, E., 2011. Women and the animal rights movement. Piscataway, NJ: Rutgers University Press.

Gawthorne, S., 2008. The women risking their lives to stop animal cruelty. CLEO, April 72-74.

Gianquitto, T., 2007. God observers of nature: American women and the scientific study of the natural world, 1820-1885. Athens, GA: University of Georgia Press.

Gimbutas, M., 1991. The civilization of the goddess: the world of Old Europe. San Francisco, CA: HarperSanFrancisco.

Glasser, C., 2011. Tied oppressions: an analysis of how sexist imagery reinforces speciesist sentiment. The Brock review, 12 (1), 51-68.

Goldman, M. and Schurman, R., 2000. Closing the "great divide": new social theory on society and nature. Annual review of sociology, 26, 563-584.

Groesz, L., Levine, M. and Murnen, S., 2002. The effect of experimental presentation of thin media images on body satisfaction: a meta-analytic review. International journal of eating disorders, 31, 1-16. 
Groves, J., 2001. Animal rights and the politics of emotion: folk constructions of emotion in the animal rights movement. In: J. Goodwin, J. Jasper and F. Polletta, eds. Passionate politics: emotions and social movements. Chicago, IL: The University of Chicago Press, 212-232.

Guither, H., 1998. Animal rights: history and scope of a radical social movement. Carbondale, IL: Southern Illinois University.

Hall, L., 2006. Capers in the churchyard: animal rights advocacy in the age of terror. Nectar Bat Press.

Haller, M., 2012. The sex secret vegans know. Men's Health News [online]. Available from: http://www.news.menshealth.com/the-sex-secret-vegans-know/2012/11/13/ [Accessed 4 December 2012].

Halverson, N., 2012. PETA's 'porn' site now live. Discovery News [online]. Available from: http://www.news.discovery.com/tech/peta-porn-site-live-120607.html [Accessed 12 December 2012].

Harper, B., 2010. Race as a "feeble matter" in veganism: interrogating whiteness, geopolitical privilege, and consumption philosophy of "cruelty-free" products. Journal for critical animal studies, 8 (3), 5-27.

Hastie, D., 2008. Banner day for whaling protest at Japan's consulate. Herald Sun [online]. Available from: $\quad$ http://www.heraldsun.com.au/news/victoria/banner-day-for-whaling-protest/story-e6frf7lo1111115243081 [Accessed 12 December 2012].

Hatton, E. and Trautner, M., 2011. Equal opportunity objectification? The sexualization of men and women on the cover of Rolling Stone. Sexuality \& culture, 15, 256-278.

Hawkins, R., 1998. Ecofeminism and nonhumans: continuity, difference, dualism, and domination. Hypatia, 13 (1), 158-197.

Holmstrom, A., 2004. The effects of the media on body image: a meta-analysis. Journal of broadcasting and electronic media, 48, 196-217.

Jackson, C., 1993. Doing what comes naturally? Women and environment in development. World development, 21 (12), 1947-1963.

Kalof, L., 1999. The effects of gender and music video imagery on sexual attitudes. Journal of social psychology, 139, 378-385.

Koss, M. et al., 1994. No safe haven: male violence against women at home, at work, and in the community. Washington, DC: American Psychological Association.

Lanis, K. and Covell, K., 1995. Images of women in advertisements: effects on attitudes related to sexual aggression. Sex roles, 32, 639-649.

Lawson, R. and Barton, S., 1980. Sex roles in social movements: a case study of the tenant movement in New York City. Signs, 6 (2), 230-247.

Lovitz, D., 2010. Muzzling a movement: the effects of anti-terrorism law, money, and politics on animal activism. Brooklyn, NY: Lantern Books.

Luke, B., 2007. Brutal: manhood and the exploitation of animals. Chicago, IL: University of Illinois Press. 
LUSH, 2007. Ask me why I'm naked. YouTube [online]. Available from: http://www.youtube.com/watch?v1/4Cm9zvaK8MOw\&feature1/4plcp [Accessed 25 November 2012].

MacKay, N. and Covell, K., 1997. The impact of women in advertisements on attitudes toward women. Sex roles, 36, 573-583.

Malamuth, N. and Check, J., 1981. The effects of mass media exposure on acceptance of violence against women: a field experiment. Journal of research in personality, 15, 436-446.

McCarthy, J. and Zald, M., 1973. The trend of social movements in America: professionalization and resource mobilization. General learning corporation.

Merchant, C., 1980. The death of nature: women, ecology, and the scientific revolution. San Francisco, CA: HarperSanFrancisco.

Mitchel, S., 2004. Frances Power Cobbe: Victorian feminist, journalist, reformer. Charlottesville, VA: University of Virginia Press.

Munro, L., 2005. Confronting cruelty: moral orthodoxy and the challenge of the animal rights movement. Leiden, NL: Brill Academic Pub.

Nibert, D., 2002. Animal rights/human rights: entanglements of oppression and liberation. Oxford: Roman \& Littlefield Publishers.

Omond, T., 2012a. Lush's human performance art was about animal cruelty not titillation. The Guardian [online]. Available from: http://www.guardian.co.uk/commentisfree/2012/apr/27/lush-animal-crueltyperformance-art [Accessed 25 November 2012].

Omond, T., 2012b. Power, oppression and abuse: performing animal tests. Fighting Animal Testing [online]. Available from: http://www.fightinganimaltesting.com/our-blog/power-oppression-and-abuseperforming-animal-tests-2/ [Accessed 25 November 2012].

Ortner, S., 1972. Is female to male as nature is to culture? Feminist studies, 1 (2), 5-31.

Peek, C., Bell, N. and Dunham, C., 1996. Gender, gender ideology, and animal rights advocacy. Gender and society, 10 (4), 464-478.

People for the Ethical Treatment of Animals, 2009. Lose the blubber: go vegetarian. The PETA Files, [online]. Available from: http://www.peta.org/b/thepetafiles/archive/2009/08/17/lose-the-blubber-govegetarian.aspx [Accessed 20 July 2012].

People for the Ethical Treatment of Animals, N.d.a. Jenna Jameson wants you to pleather yourself. Features [online]. Available from: http://www.peta.org/features/jenna-jameson-pleatheryourself.aspx [Accessed 25 November 2012].

People for the Ethical Treatment of Animals, N.d.b. Why does PETA sometimes use nudity in its campaigns? Frequently Asked Questions [online]. Available from: http://www.peta.org/about/faq/Whydoes-PETA-sometimes-use-nudity-in-its-campaigns.aspx [Accessed 12 August 2012].

Pinsker, B., 2008. Naked packaging, naked employees - is Lush the ultimate green product? Daily Finance [online]. Available from: http://www.dailyfinance.com/2008/08/27/naked-packagingnakedemployees-is-lush-the-ultimate-green-p/ [Accessed 24 November 2012]. 
Preventing Rape by Intoxication Through Community Education, 2009. Prevention. Knowtheprice.org [online]. Available from: http://www.knowtheprice.org/prevention/ [Accessed 25 November 2012].

Price, J., 1999. Flight maps: adventures with nature in modern America. New York, NY: Basic Books.

Reynolds, C. and Haslam, N., 2011. Evidence for an association between women and nature: an analysis of media images and mental representations. Ecopsychology, 3 (1), 59-64.

ScienceDaily, 2007. Alcohol is most common 'date rape' drug. Science News [online]. Available from: http://www.sciencedaily.com/releases/2007/10/071020113144.htm [Accessed 25 November 2012].

Sherrow, M., 2011. Splish splash, PETA UK's takin' a bath. The PETA Files [online]. Available from: http://www.peta.org/b/thepetafiles/archive/2011/03/22/splish-splash-peta-s-takin-a-bath.aspx [Accessed 12 December 2012].

Shoemaker, P. and Reese, S., 1996. Mediating the message: theories of influences on mass media content. 2nd ed. White Plains, NY: Longman Publishers.

Staggenborg, S., 1988. The consequences of professionalization and formalization in the pro-choice movement. American sociological review, 53 (4), 585-605.

The Age, 2007. Animal rights activists target conference. National [online]. Available from: http://www.theage.com.au/news/national/animal-rights-activists-target-

conference/2007/07/10/1183833498634.html [Accessed 12 December 2012].

The Age, 2008. Naked protest against suf-fur-ing. Life \& Style [online]. Available from: http://www.theage.com.au/lifestyle/life/naked-protest-against-suffuring-20090407-9z7v.html [Accessed 12 December 2012].

Torres, B., 2006. Making a killing: the political economy of animal rights. Oakland, CA: AK Press.

Turner, S. et al., 1997. The influence of fashion magazines on the body image satisfaction of college women: an exploratory analysis. Adolescence, 32, 603-614.

Unger, N., 2012. Beyond nature's housekeepers: American women in environmental history. New York, NY: Oxford University Press.

Ward, L., 2002. Does television exposure affect emerging adults' attitudes and assumptions about sexual relationships? Correlational and experimental confirmation. Journal of youth \& adolescence, 31, 1-15.

West, G. and Blumberg, R., eds, 1990. Women and social protest. New York, NY: Oxford University Press.

Zald, M. and Ash, R., 1966. Social movement organizations: growth, decay and change. Social forces, 44 (3), 327-341. 